\title{
Robust design of wastewater systems at regional level
}

\author{
J. Zeferino, M. da Conceição Cunha \& A. Antunes \\ Department of Civil Engineering, Coimbra University, Portugal
}

\begin{abstract}
Wastewater systems are of crucial importance in the promotion of sustainable development. Their implementation is very complex because there are many different issues to be considered simultaneously (environmental, economical, social, and technical). The Water Framework Directive (WFD) brought new challenges to the definition of appropriate designs for such systems. In particular, they should be determined so that they are capable of performing well even during extreme events. Therefore, the uncertainty inherent to the water environments where the wastewater systems are included must be considered since the beginning of the decision processes where these systems are dealt with. In this paper is presented a robust optimization model for helping to define the configuration of sewer networks and the location and size of the treatment plants where the effluent carried by the sewers will be processed before being discharged into some water body. Its application to a case study illustrates how the model can be used to analyze the implications of increasing the reliability of wastewater systems upon the costs of these systems.
\end{abstract}

Keywords: wastewater system, optimization model, robustness.

\section{Introduction}

The good performance of wastewater systems is critically important for the accomplishment of sustainable development goals, and, more specifically, for the attainment of the "good ecological status" envisaged by the WFD (EC [1]). The many different facets (environmental, economical, social, technical) to consider for establishing these systems should be embraced in an integrated manner. Decision models are essential tools for the study of this kind of systems, since they are able to incorporate all those facets in systematic way. The 
vulnerability of the water systems where the wastewater systems are included requires decisions, which are able to cope with very adverse situations. Therefore the uncertainty that characterizes water systems should be considered in decision processes since their beginning. In fact, the preparedness phase represented in the risk cycle of Figure 1 is a crucial moment for introducing in the wastewater systems the level of robustness that will allow them to perform well even under unfavourable conditions. Robust optimization models (Mulvey et al. [2] and Laguna [3]) are scenario-based models capable of finding solutions that take uncertainty into account.

In this paper is presented a robust optimization model for wastewater system planning. The model is aimed at assisting environmental authorities in decision processes involving both the configuration of sewer networks and the location and sizing of the set of the treatment plants where the effluent carried by the sewers will be processed before being discharged into some river (or other water body). The application of the model to a case study allows a trade-off analysis between decreasing the level of vulnerability of the water system and the costs involved in the construction, maintenance, and operation of the wastewater system.

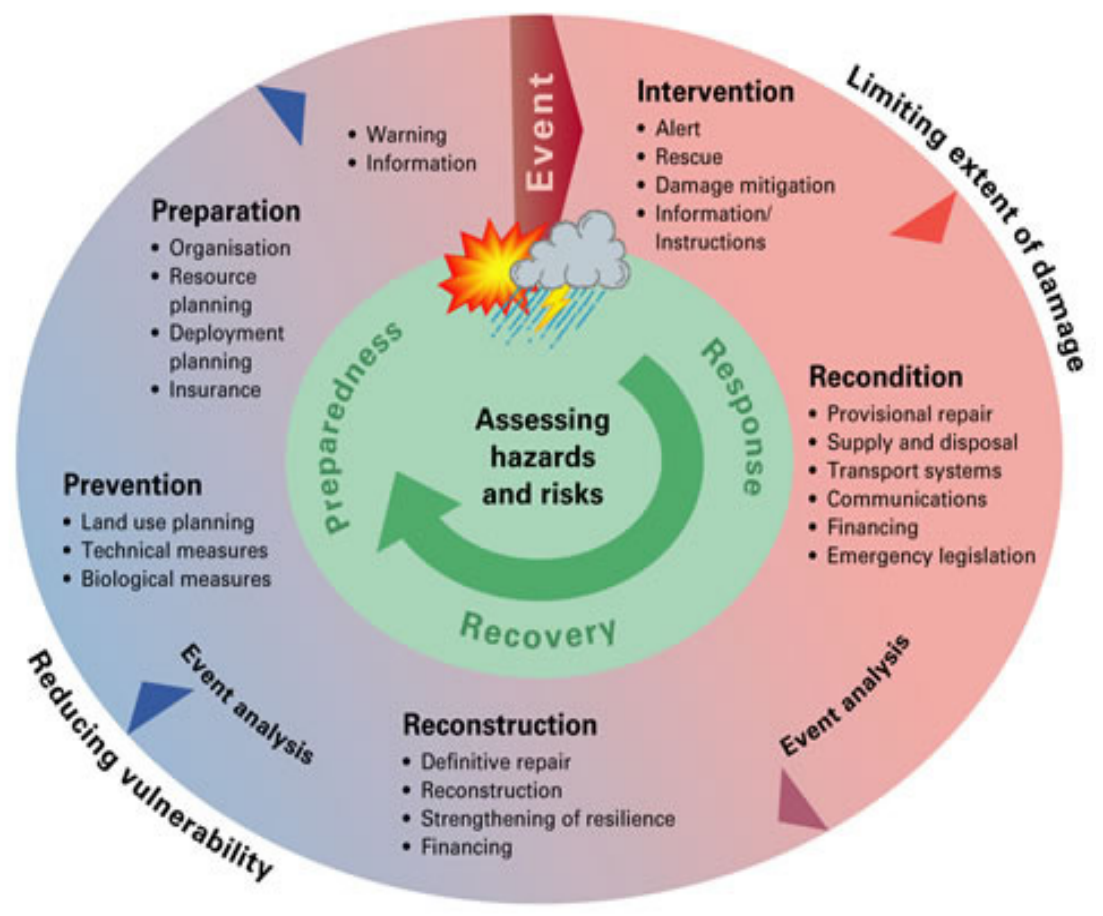

Figure 1: The risk cycle (OFPP [4]). 


\section{Robust optimization model}

The objective function of the proposed robust optimization model includes two terms. The first term represents the costs of the solution to be implemented and the second term represents a penalty for the performance of an environmental indicator - dissolved oxygen (DO) - for all scenarios that can occur during the wastewater system life span. The performance of such indicator is highly dependent on the solution adopted.

The mathematical formulation of the function has the following form:

$$
\min C(\boldsymbol{x})+\theta \times\left[\sum_{s \in S}\left(p_{s} \times \sum_{k \in K} l_{k} \times \max \left\{0 ; D O_{k, \min s}-D O_{k, \min }(\boldsymbol{x})\right\}^{2}\right)\right]
$$

where $C(\boldsymbol{x})$ is the cost of the solution to be implemented as a function of the decisions regarding the location and size of treatment plants and the configuration of the sewer network (these decisions are generically represented with variables $\boldsymbol{x}$ ), $\theta$ is the penalty applicable to the violation of water quality standards; $S$ is the set of scenarios; $p_{s}$ is probability of scenario $s ; K$ is the set os river sections, $l_{k}$ is the length of section $k ; D O_{k, \min s}$ is the $\mathrm{DO}$ in river section $k$ when the wastewater system is designed to maximize the minimum DO in the river if scenario $s$ occurs; $D O_{k, \min }(\boldsymbol{x})$ is the value of the minimum DO for the solution to be implemented.

This objective function is subjected to different types of constraints (Cunha et al. [5]). There are constraints to ensure that the sewer network will be sized according to hydraulic laws and regulations, and constraints to ensure that the treated effluent discharged from each treatment plant will not create environmental damages. A water quality model is used to evaluate the effects of effluent discharges in a river. To evaluate dissolved oxygen values, the water quality model considers the following aspects: atmospheric reaeration, photosynthesis, respiration, sediment oxygen demand, carbonaceous organic matter oxidation, and nitrification.

\section{Case study}

In order to test the model, we formulated a case study using partly-random rules regarding the shape and topography of regions, the location and size of population centers, and the location of treatment plants. These rules, which intend to mimic real-world situations, are explained in Zeferino et al. [6].

The case study involves a rectangular region with approximately $197 \mathrm{~km}$ along a river and $71 \mathrm{~km}$ in the perpendicular direction (see Figures 1 and 2). A total of 66 nodes were considered, including 11 possible locations for wastewater treatment plants. Within the remaining nodes, 31 correspond to population centers (the wastewater sources). The total population of the region is approximately 884,000 . The per capita wastewater generation rate per inhabitant is assumed to be 200 liters. 


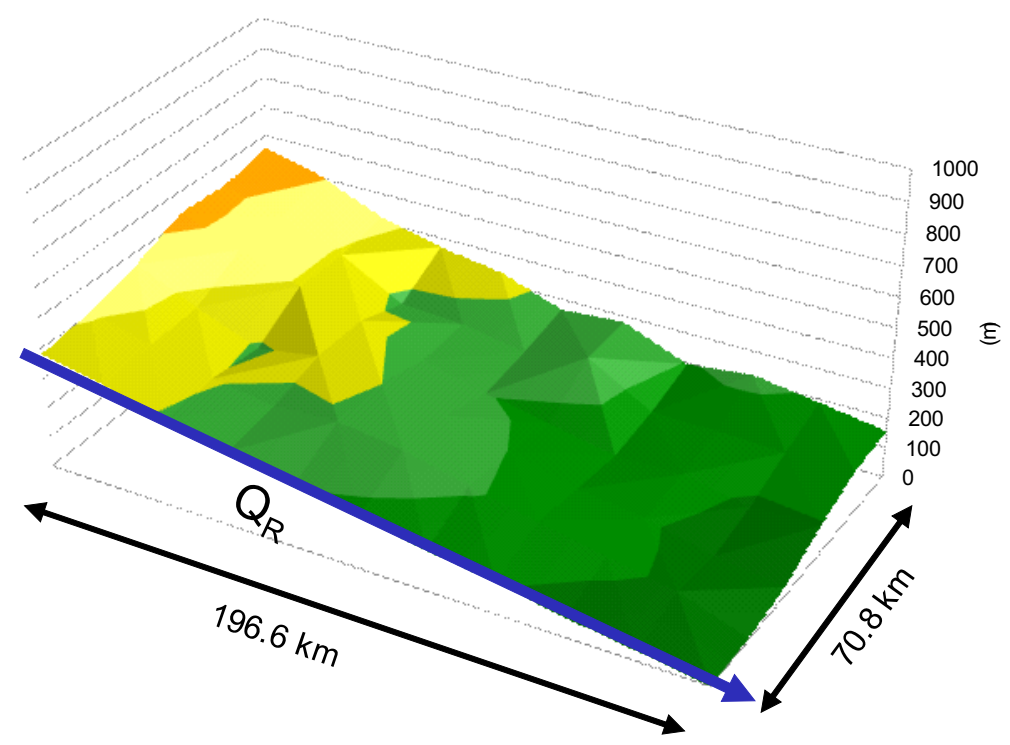

Figure 2: $\quad$ Topography of the case study region.

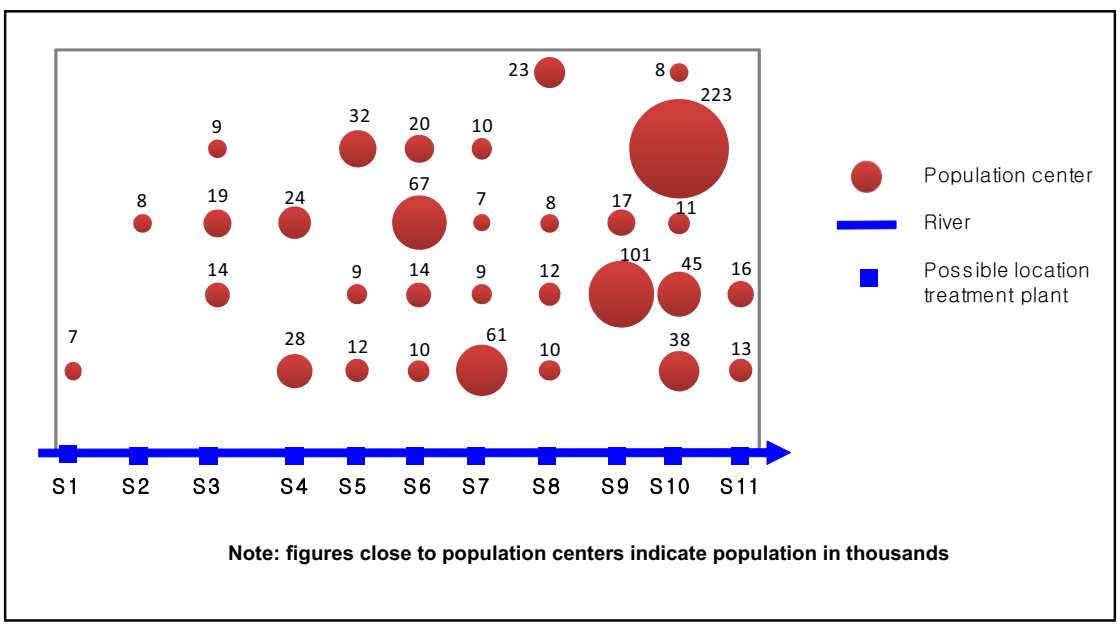

Figure 3: Spatial distribution of population and possible location for treatment plants in the case study region.

The water quality in the river depends on the wastewater discharged into the river and on the river flow when the discharges are made. As one could expect, the larger the flow in the river, the smaller the water quality damages will be. For 
a given wastewater discharge, if the river flow is low there may be a violation of water quality standards. At the limit, if there was no flow at all, the quality of the water in the river would be the same as the quality of effluent discharged from wastewater treatment plants.

Depending on the river flow and the applicable water quality standards, the optimal configuration for the wastewater system can vary substantially. For this study, water quality is assessed through the lowest DO in the river. When the river flow is sufficiently large, the optimal configuration only depends on costminimization issues, encompassing few treatment plants (to achieve economies of scale), short sewer networks, and few (or no) pump stations. While river flow decreases, water quality constraints need to be taken into account, which leads to more costly optimal configurations. Thus, for scenarios involving a small river flow, the wastewater must be more widely dispersed, in order to reduce environmental impacts. With treatment plants scattered along the river, impacts are mitigated. However, in principle, this implies more expensive solutions, since sewer networks would have to be longer and some pump stations could be necessary.

For the case study we assumed the expected river flow to follow a normal distribution with mean $12 \mathrm{~m}^{3} / \mathrm{s}$ and variance $6 \mathrm{~m}^{3} / \mathrm{s}$. After discretization, we considered 20 scenarios, with flows comprised between $3 \mathrm{~m}^{3} / \mathrm{s}$ and $20 \mathrm{~m}^{3} / \mathrm{s}$ (Table 1). In a deterministic analysis, instead of considering the variability of the flows one would proceed using some reference value for the river flow (expected value, worst-case, etc.).

The values of $D O_{k, \min s}$ used for the case study are also presented in Table 1. These values were calculated using a model for maximizing the minimum dissolved oxygen for each scenario to serve as reference values in the penalty term of objective function (1). For instance, if the river flow is $3 \mathrm{~m}^{3} / \mathrm{s}$, the wastewater system can be designed to achieve a DO of $5.47 \mathrm{mg} / \mathrm{l}$ in section 1 . As one could expect, this value increases when the flow increases, reaching $8.14 \mathrm{mg} / 1$ when the river flow attains $20 \mathrm{~m}^{3} / \mathrm{s}$.

Table 1.

\begin{tabular}{|c|c|c|c|c|c|c|c|c|c|c|c|c|c|c|c|c|c|c|}
\hline \multirow{3}{*}{ Section } & \multicolumn{18}{|c|}{$\mathrm{QR}(\mathrm{m} 3 / \mathrm{s})$} \\
\hline & 3 & 4 & 5 & 6 & 7 & 8 & 9 & 10 & 11 & 12 & 13 & 14 & 15 & 16 & 17 & 18 & 19 & 20 \\
\hline & \multicolumn{18}{|c|}{$\mathrm{DO}_{\mathrm{k}, \operatorname{mins}}(\mathrm{mg} / \mathrm{l})$} \\
\hline 1 & 5.47 & 6.12 & 6.50 & 6.84 & 7.10 & 7.23 & 7.38 & 7.51 & 7.61 & 7.71 & 7.79 & 7.87 & 7.92 & 7.97 & 8.02 & 8.06 & 8.11 & 8.14 \\
\hline 2 & 5.15 & 5.81 & 6.18 & 6.53 & 6.80 & 6.94 & 7.09 & 7.23 & 7.33 & 7.44 & 7.53 & 7.62 & 7.67 & 7.73 & 7.78 & 7.83 & 7.88 & 7.92 \\
\hline 3 & 5.17 & 5.82 & 6.18 & 6.53 & 6.74 & 6.93 & 7.08 & 7.22 & 7.32 & 7.42 & 7.51 & 7.60 & 7.65 & 7.70 & 7.75 & 7.80 & 7.85 & 7.89 \\
\hline 4 & 5.62 & 5.99 & 6.25 & 6.48 & 6.74 & 6.97 & 7.16 & 7.24 & 7.36 & 7.45 & 7.50 & 7.58 & 7.64 & 7.72 & 7.77 & 7.81 & 7.85 & 7.89 \\
\hline 5 & 5.13 & 5.84 & 6.32 & 6.49 & 6.83 & 6.95 & 7.10 & 7.22 & 7.42 & 7.44 & 7.56 & 7.62 & 7.68 & 7.70 & 7.78 & 7.82 & 7.86 & 7.90 \\
\hline 6 & 5.11 & 5.87 & 6.22 & 6.54 & 6.73 & 6.98 & 7.11 & 7.25 & 7.40 & 7.46 & 7.52 & 7.58 & 7.65 & 7.72 & 7.77 & 7.81 & 7.85 & 7.89 \\
\hline 7 & 5.23 & 5.77 & 6.23 & 6.63 & 6.74 & 6.97 & 7.12 & 7.22 & 7.34 & 7.44 & 7.51 & 7.58 & 7.65 & 7.71 & 7.80 & 7.83 & 7.88 & 7.91 \\
\hline 8 & 5.54 & 5.79 & 6.41 & 6.73 & 6.87 & 7.00 & 7.18 & 7.24 & 7.37 & 7.47 & 7.57 & 7.66 & 7.72 & 7.72 & 7.89 & 7.90 & 7.96 & 7.99 \\
\hline 9 & 5.82 & 6.05 & 6.74 & 6.81 & 7.12 & 7.17 & 7.35 & 7.38 & 7.49 & 7.58 & 7.71 & 7.79 & 7.85 & 7.82 & 8.01 & 8.01 & 8.07 & 8.09 \\
\hline 10 & 6.17 & 6.36 & 7.02 & 6.99 & 7.34 & 7.35 & 7.52 & 7.53 & 7.63 & 7.71 & 7.84 & 7.92 & 7.96 & 7.92 & 8.12 & 8.11 & 8.17 & 8.18 \\
\hline 11 & 5.12 & 5.76 & 6.17 & 6.47 & 6.73 & 6.93 & 7.08 & 7.22 & 7.32 & 7.42 & 7.50 & 7.58 & 7.64 & 7.70 & 7.75 & 7.80 & 7.85 & 7.88 \\
\hline
\end{tabular}




\section{Model results}

The robust optimization model presented in Section 2 has been solved for different values of the penalty $\theta$ with the simulated annealing algorithm described in [6].

The results obtained for the optimal DO are shown in Tables $2-4$. The values depicted in bold in these tables are those that were penalized in the

Table 2: $\quad$ Values for optimal $D O_{\mathrm{k}, \min }$ with $\theta=0$.

\begin{tabular}{|c|c|c|c|c|c|c|c|c|c|c|c|c|c|c|c|c|c|c|}
\hline \multirow{3}{*}{ Section } & \multicolumn{18}{|c|}{$\mathrm{QR}(\mathrm{m} 3 / \mathrm{s})$} \\
\hline & 3 & 4 & 5 & 6 & 7 & 8 & 9 & 10 & 11 & 12 & 13 & 14 & 15 & 16 & 17 & 18 & 19 & 20 \\
\hline & \multicolumn{18}{|c|}{$\mathrm{DO}_{\mathrm{k}, \min \mathrm{s}}(\mathrm{mg} / \mathrm{l})$} \\
\hline 1 & 8.61 & 8.64 & 8.66 & 8.68 & 8.69 & 8.70 & 8.71 & 8.72 & 8.73 & 8.73 & 8.74 & 8.74 & 8.75 & 8.75 & 8.75 & 8.76 & 8.76 & 8.76 \\
\hline 2 & 8.59 & 8.61 & 8.63 & 8.64 & 8.64 & 8.65 & 8.65 & 8.65 & 8.66 & 8.66 & 8.66 & 8.67 & 8.67 & 8.67 & 8.67 & 8.67 & 8.68 & 8.68 \\
\hline 3 & 8.62 & 8.63 & 8.63 & 8.64 & 8.64 & 8.65 & 8.65 & 8.65 & 8.66 & 8.66 & 8.66 & 8.66 & 8.66 & 8.66 & 8.67 & 8.67 & 8.67 & 8.67 \\
\hline 4 & 7.88 & 8.09 & 8.22 & 8.31 & 8.37 & 8.41 & 8.44 & 8.47 & 8.49 & 8.51 & 8.52 & 8.53 & 8.54 & 8.55 & 8.56 & 8.57 & 8.57 & 8.58 \\
\hline 5 & 7.85 & 8.07 & 8.20 & 8.29 & 8.35 & 8.40 & 8.43 & 8.46 & 8.48 & 8.50 & 8.52 & 8.53 & 8.54 & 8.55 & 8.56 & 8.57 & 8.57 & 8.58 \\
\hline 6 & 7.88 & 8.09 & 8.22 & 8.30 & 8.37 & 8.41 & 8.44 & 8.47 & 8.49 & 8.51 & 8.53 & 8.54 & 8.55 & 8.56 & 8.57 & 8.57 & 8.58 & 8.59 \\
\hline 7 & 5.63 & 6.30 & 6.74 & 7.05 & 7.28 & 7.46 & 7.60 & 7.72 & 7.81 & 7.89 & 7.95 & 8.01 & 8.06 & 8.11 & 8.14 & 8.18 & 8.21 & 8.23 \\
\hline 8 & 5.40 & 6.10 & 6.56 & 6.89 & 7.13 & 7.32 & 7.47 & 7.60 & 7.70 & 7.79 & 7.86 & 7.92 & 7.98 & 8.03 & 8.07 & 8.11 & 8.14 & 8.17 \\
\hline 9 & 5.44 & 6.12 & 6.57 & 6.89 & 7.14 & 7.33 & 7.47 & 7.60 & 7.70 & 7.79 & 7.86 & 7.92 & 7.98 & 8.03 & 8.07 & 8.11 & 8.14 & 8.17 \\
\hline 10 & 5.72 & 6.32 & 6.72 & 7.01 & 7.23 & 7.40 & 7.54 & 7.65 & 7.74 & 7.83 & 7.89 & 7.95 & 8.01 & 8.05 & 8.09 & 8.13 & 8.16 & 8.19 \\
\hline 11 & 3.24 & 4.13 & 4.77 & 5.26 & 5.64 & 5.95 & 6.20 & 6.42 & 6.60 & 6.76 & 6.89 & 7.01 & 7.12 & 7.21 & 7.30 & 7.37 & 7.44 & 7.50 \\
\hline
\end{tabular}

Table 3: $\quad$ Values for optimal $D O_{\mathrm{k}, \min }$ with $\theta=10^{3}$.

\begin{tabular}{|c|c|c|c|c|c|c|c|c|c|c|c|c|c|c|c|c|c|c|}
\hline \multirow{3}{*}{ Section } & \multicolumn{18}{|c|}{$\mathrm{QR}(\mathrm{m} 3 / \mathrm{s})$} \\
\hline & 3 & 4 & 5 & 6 & 7 & 8 & 9 & 10 & 11 & 12 & 13 & 14 & 15 & 16 & 17 & 18 & 19 & 20 \\
\hline & \multicolumn{18}{|c|}{$\mathrm{DO}_{\mathrm{k}, \operatorname{mins}(\mathrm{mg} / \mathrm{l})}$} \\
\hline 1 & 8.61 & 8.64 & 8.66 & 8.68 & 8.69 & 8.70 & 8.71 & 8.72 & 8.73 & 8.73 & 8.74 & 8.74 & 8.75 & 8.75 & 8.75 & 8.76 & 8.76 & 8.76 \\
\hline 2 & 8.56 & 8.59 & 8.61 & 8.62 & 8.63 & 8.63 & 8.64 & 8.64 & 8.65 & 8.65 & 8.66 & 8.66 & 8.66 & 8.67 & 8.67 & 8.67 & 8.67 & 8.67 \\
\hline 3 & 5.63 & 6.31 & 6.75 & 7.05 & 7.28 & 7.45 & 7.58 & 7.69 & 7.78 & 7.86 & 7.92 & 7.98 & 8.03 & 8.07 & 8.10 & 8.14 & 8.17 & 8.19 \\
\hline 4 & 5.49 & 6.18 & 6.63 & 6.94 & 7.17 & 7.35 & 7.49 & 7.61 & 7.70 & 7.78 & 7.85 & 7.91 & 7.96 & 8.00 & 8.04 & 8.08 & 8.11 & 8.14 \\
\hline 5 & 5.53 & 6.20 & 6.64 & 6.95 & 7.18 & 7.35 & 7.49 & 7.61 & 7.70 & 7.78 & 7.85 & 7.90 & 7.96 & 8.00 & 8.04 & 8.07 & 8.11 & 8.13 \\
\hline 6 & 4.76 & 5.49 & 6.00 & 6.36 & 6.65 & 6.87 & 7.04 & 7.19 & 7.31 & 7.42 & 7.51 & 7.59 & 7.66 & 7.72 & 7.77 & 7.82 & 7.86 & 7.90 \\
\hline 7 & 4.74 & 5.47 & 5.98 & 6.34 & 6.63 & 6.85 & 7.03 & 7.17 & 7.30 & 7.40 & 7.49 & 7.57 & 7.64 & 7.70 & 7.76 & 7.81 & 7.85 & 7.89 \\
\hline 8 & 4.89 & 5.58 & 6.06 & 6.41 & 6.68 & 6.89 & 7.06 & 7.20 & 7.32 & 7.43 & 7.51 & 7.59 & 7.66 & 7.72 & 7.77 & 7.82 & 7.87 & 7.90 \\
\hline 9 & 5.38 & 5.97 & 6.38 & 6.67 & 6.90 & 7.09 & 7.23 & 7.35 & 7.46 & 7.55 & 7.62 & 7.69 & 7.75 & 7.81 & 7.86 & 7.90 & 7.94 & 7.97 \\
\hline 10 & 5.85 & 6.34 & 6.68 & 6.93 & 7.13 & 7.29 & 7.41 & 7.51 & 7.60 & 7.68 & 7.75 & 7.81 & 7.86 & 7.91 & 7.95 & 7.99 & 8.02 & 8.05 \\
\hline 11 & 4.41 & 5.10 & 5.59 & 5.96 & 6.26 & 6.50 & 6.69 & 6.85 & 6.99 & 7.12 & 7.22 & 7.31 & 7.40 & 7.47 & 7.54 & 7.60 & 7.65 & 7.70 \\
\hline
\end{tabular}

Table 4: $\quad$ Values for optimal $D O_{\mathrm{k}, \min }$ with $\theta=10^{6}$.

\begin{tabular}{|c|c|c|c|c|c|c|c|c|c|c|c|c|c|c|c|c|c|c|}
\hline \multirow{3}{*}{ Section } & \multicolumn{18}{|c|}{$\mathrm{QR}_{\mathrm{R}}(\mathrm{m} 3 / \mathrm{s})$} \\
\hline & 3 & 4 & 5 & 6 & 7 & 8 & 9 & 10 & 11 & 12 & 13 & 14 & 15 & 16 & 17 & 18 & 19 & 20 \\
\hline & \multicolumn{18}{|c|}{$\mathrm{DO}_{\mathrm{k}, \min \mathrm{s}}$} \\
\hline 1 & 5.22 & 5.95 & 6.44 & 6.80 & 7.06 & 7.26 & 7.43 & 7.56 & 7.67 & 7.76 & 7.84 & 7.91 & 7.97 & 8.03 & 8.07 & 8.12 & 8.15 & 8.19 \\
\hline 2 & 4.85 & 5.61 & 6.12 & 6.48 & 6.75 & 6.97 & 7.14 & 7.29 & 7.40 & 7.51 & 7.59 & 7.67 & 7.74 & 7.79 & 7.85 & 7.89 & 7.94 & 7.97 \\
\hline 3 & 4.88 & 5.61 & 6.12 & 6.48 & 6.75 & 6.97 & 7.14 & 7.28 & 7.39 & 7.49 & 7.58 & 7.65 & 7.72 & 7.77 & 7.82 & 7.87 & 7.91 & 7.94 \\
\hline 4 & 5.26 & 5.87 & 6.29 & 6.60 & 6.84 & 7.03 & 7.18 & 7.30 & 7.41 & 7.50 & 7.58 & 7.65 & 7.71 & 7.77 & 7.81 & 7.86 & 7.90 & 7.93 \\
\hline 5 & 5.37 & 5.93 & 6.32 & 6.61 & 6.83 & 7.01 & 7.16 & 7.28 & 7.38 & 7.47 & 7.55 & 7.61 & 7.67 & 7.73 & 7.78 & 7.82 & 7.86 & 7.89 \\
\hline 6 & 5.35 & 5.91 & 6.30 & 6.59 & 6.82 & 6.99 & 7.14 & 7.26 & 7.36 & 7.45 & 7.53 & 7.60 & 7.66 & 7.71 & 7.76 & 7.80 & 7.85 & 7.88 \\
\hline 7 & 5.40 & 5.94 & 6.33 & 6.61 & 6.83 & 7.00 & 7.14 & 7.26 & 7.37 & 7.46 & 7.53 & 7.60 & 7.66 & 7.71 & 7.76 & 7.80 & 7.85 & 7.88 \\
\hline 8 & 5.56 & 6.08 & 6.44 & 6.71 & 6.92 & 7.09 & 7.22 & 7.33 & 7.43 & 7.52 & 7.59 & 7.65 & 7.71 & 7.76 & 7.81 & 7.85 & 7.89 & 7.92 \\
\hline 9 & 5.98 & 6.43 & 6.74 & 6.97 & 7.15 & 7.29 & 7.40 & 7.50 & 7.59 & 7.66 & 7.72 & 7.78 & 7.83 & 7.87 & 7.91 & 7.95 & 7.98 & 8.01 \\
\hline 10 & 6.36 & 6.75 & 7.01 & 7.20 & 7.36 & 7.48 & 7.58 & 7.66 & 7.73 & 7.80 & 7.85 & 7.89 & 7.94 & 7.98 & 8.01 & 8.04 & 8.07 & 8.10 \\
\hline 11 & 5.21 & 5.77 & 6.17 & 6.47 & 6.72 & 6.91 & 7.06 & 7.19 & 7.30 & 7.40 & 7.48 & 7.56 & 7.62 & 7.68 & 7.74 & 7.79 & 7.83 & 7.87 \\
\hline
\end{tabular}




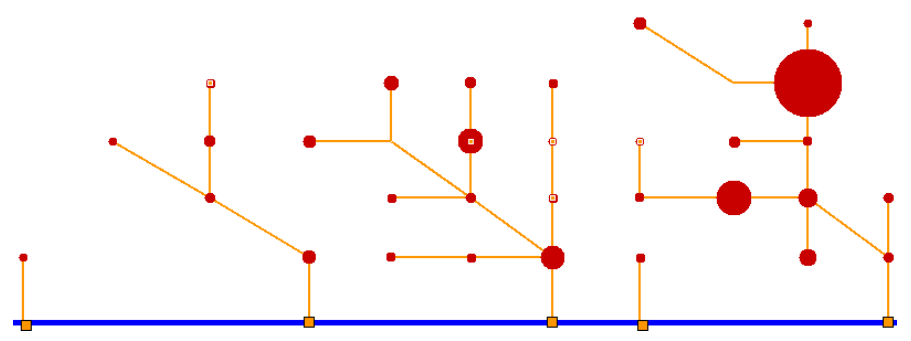

a) $\theta=0$, cost $=231.42 \mathrm{M} €$

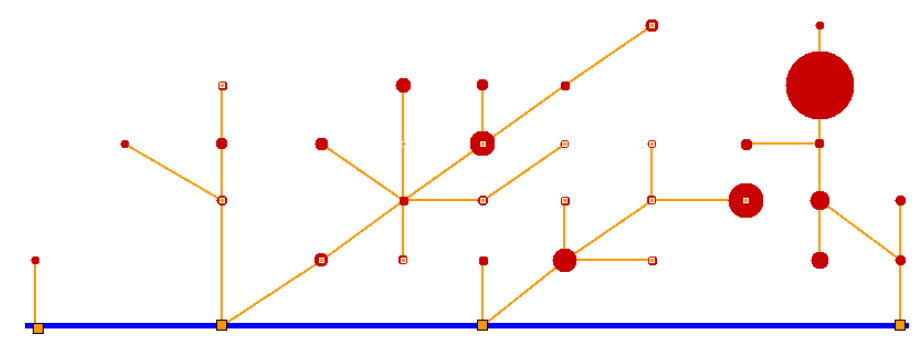

b) $\theta=10^{3}$, cost $=283.03 \mathrm{M} €$

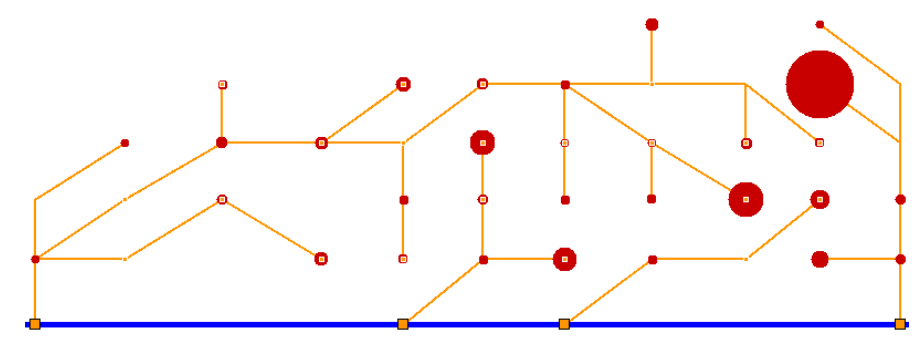

c) $\theta=10^{6}$, cost $=441.47 \mathrm{M} €$

\begin{tabular}{lll} 
Sewer & Population center & Pump station \\
\hline River & $\quad \begin{array}{l}\text { Population center with } \\
\text { pump station }\end{array}$
\end{tabular}

Figure 4: Optimum design of the wastewater system for different values of the penalty coefficient.

objective function, since thay are smaller than the reference values depicted in Table 1. It is clear that as the penalty coefficient increases, the dissolved oxygen increases. In Table 4, where the values for the highest penalty coefficient are 
depicted, even for very extreme flow events (left columns) the level of dissolved oxygen is close to the best possible (i.e., the reference values). The corresponding solution is more robust, and its implementation will decrease the vulnerability of the water system. However, as shown in Figure 4, where the optimum design of the wastewater system is displayed for different levels of $\theta$, costs increase as the solution becomes more robust.

Table 1: $\quad$ Optimum discharges from the wastewater treatment plants.

\begin{tabular}{|c|c|c|c|c|c|c|c|c|c|c|c|c|c|c|c|c|c|c|}
\hline \multirow{3}{*}{ Section } & \multicolumn{18}{|c|}{$\mathrm{QR}_{\mathrm{R}}(\mathrm{m} 3 / \mathrm{s})$} \\
\hline & 3 & 4 & 5 & 6 & 7 & 8 & 9 & 10 & 11 & 12 & 13 & 14 & 15 & 16 & 17 & 18 & 19 & 20 \\
\hline & \multicolumn{18}{|c|}{$\mathrm{Qk}_{\mathrm{k}}(\mathrm{m} 3 / \mathrm{s})$} \\
\hline 1 & 804 & 820 & 866 & 868 & 866 & 911 & 924 & 930 & 947 & 948 & 948 & 942 & 957 & 965 & 966 & 967 & 961 & 967 \\
\hline 2 & 0 & 0 & 0 & 0 & 0 & 0 & 0 & 0 & 0 & 0 & 0 & 0 & 0 & 0 & 0 & 0 & 0 & 0 \\
\hline 3 & 0 & 0 & 0 & 0 & 64 & 0 & 0 & 0 & 0 & 0 & 0 & 0 & 0 & 0 & 0 & 0 & 0 & 0 \\
\hline 4 & 0 & 155 & 178 & 239 & 109 & 98 & 0 & 85 & 0 & 28 & 93 & 104 & 64 & 0 & 0 & 0 & 33 & 0 \\
\hline 5 & 470 & 206 & 0 & 24 & 0 & 198 & 318 & 194 & 170 & 230 & 0 & 0 & 44 & 240 & 165 & 174 & 136 & 168 \\
\hline 6 & 0 & 0 & 308 & 142 & 338 & 0 & 0 & 0 & 142 & 0 & 304 & 313 & 271 & 0 & 142 & 142 & 142 & 142 \\
\hline 7 & 0 & 284 & 0 & 0 & 0 & 240 & 165 & 256 & 187 & 240 & 45 & 0 & 23 & 242 & 0 & 23 & 0 & 0 \\
\hline 8 & 104 & 0 & 0 & 192 & 0 & 0 & 0 & 0 & 0 & 0 & 0 & 0 & 0 & 0 & 0 & 0 & 0 & 0 \\
\hline 9 & 0 & 0 & 0 & 0 & 0 & 0 & 0 & 0 & 0 & 0 & 0 & 0 & 0 & 0 & 0 & 0 & 0 & 0 \\
\hline 10 & 0 & 0 & 0 & 0 & 0 & 0 & 0 & 0 & 0 & 0 & 0 & 0 & 0 & 0 & 0 & 0 & 0 & 0 \\
\hline 11 & 668 & 581 & 694 & 581 & 668 & 600 & 639 & 581 & 600 & 600 & 657 & 687 & 687 & 600 & 773 & 740 & 773 & 769 \\
\hline
\end{tabular}

a) For all the scenarios taken independently

\begin{tabular}{cccc}
\hline Section & $\theta=0$ & $\theta=10^{3}$ & $\theta=10^{6}$ \\
\hline 1 & 17 & 17 & 879 \\
2 & 0 & 0 & 0 \\
3 & 0 & 683 & 0 \\
4 & 178 & 0 & 0 \\
5 & 0 & 0 & 352 \\
6 & 0 & 490 & 0 \\
7 & 640 & 0 & 127 \\
8 & 23 & 0 & 0 \\
9 & 0 & 0 & 0 \\
10 & 0 & 0 & 0 \\
11 & 1188 & 856 & 687 \\
\hline
\end{tabular}

b) For different levels of penalties of the robust model

The values of the optimum discharges $\left(Q_{k}\right)$ at the wastewater treatment plants that should be included in the system are presented in Table 5, for each one of the scenarios taken independently and for all the scenarios considered in the resolution of the robust model for each one of the penalties. As it could be expected, as the penalty coefficient increases discharges tend to be less concentrated in the last section, and become more evenly distributed along the river.

\section{Conclusions}

In this paper, we presented an optimization model aimed to assist authorities at finding robust solutions for wastewater systems - a kind of system that plays a crucial role in environmental management. Traditionally, wastewater systems 
planning models have focused on cost minimization. Recently, they started to encompass other objectives, including environmental objectives (see [7] for a survey of multi-objective models). However, to our best knowledge, robustness issues have rarely (if ever) been incorporated into this type of models. The fact that our model can deal explicitly with the uncertainty that characterizes future states of the world, makes it a valuable tool in times when the public is less and less indulgent with failures regarding economic and environmental decisions.

\section{References}

[1] EC, Directive 2000/60/EC of the European Parliament and of the Council of 23 October 2000 establishing a framework for Community action in the field of water policy, Official Journal of the European Communities, L327, pp. 1$72,2000$.

[2] Mulvey, J.M., Vanderbei, R.J., Zenios, S.A., Robust optimization of largescale systems, Operations Research, 43(2), 264-281, 1995.

[3] Laguna, M., Applying robust optimization to capacity expansion of one location in telecommunications with demand uncertainty, Management Science, 44 (11), S101-S110, 1998.

[4] OFPP - Office Fédéral de la Protection de la Population. Catastrophes et situation d'urgence en Suisse: une appréciation des risques du point de vue de la protection de la population, Berne, 2003.

[5] Cunha, M.C., Pinheiro, L., Zeferino, J., Antunes, A., Afonso, A., An optimization model for integrated regional wastewater systems planning, Journal of Water Resources Planning and Management ASCE, 135 (1), pp. 23-33, 2009.

[6] Zeferino, J.A., Antunes, A.P., Cunha, M.C., An efficient simulated annealing algorithm for regional wastewater system planning, ComputerAided Civil and Infrastructure Engineering, in press.

[7] Zeferino, J.A., Antunes, A.P., Cunha, M.C., "Multi-objective model for regional wastewater systems planning", Civil Engineering and Environmental Systems, in press. 